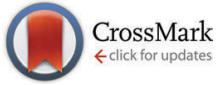

Cite this: Phys. Chem. Chem. Phys., 2016, 18, 6291

Received 26th November 2015, Accepted 20th January 2016

DOI: $10.1039 / c 5 c p 07298 k$

www.rsc.org/pccp

\section{Structural determination of niobium-doped silicon clusters by far-infrared spectroscopy and theory $\dagger$}

\author{
Xiaojun Li, ${ }^{* a}$ Pieterjan Claes, ${ }^{b}$ Marko Haertelt, ${ }^{c}$ Peter Lievens, ${ }^{b}$ Ewald Janssens* ${ }^{\text {b }}$ \\ and André Fielicke*cd
}

\begin{abstract}
In this work, the structures of cationic $\mathrm{Si}_{n} \mathrm{Nb}^{+}(n=4-12)$ clusters are determined using the combination of infrared multiple photon dissociation (IR-MPD) and density functional theory (DFT) calculations. The experimental IR-MPD spectra of the argon complexes of $\mathrm{Si}_{n} \mathrm{Nb}^{+}$are assigned by comparison to the calculated IR spectra of low-energy structures of $\mathrm{Si}_{n} \mathrm{Nb}^{+}$that are identified using the stochastic 'random kick' algorithm in conjunction with the BP86 GGA functional. It is found that the Nb dopant tends to bind in an apex position of the $\mathrm{Si}_{n}$ framework for $n=4-9$ and in surface positions with high coordination numbers for $n=10-12$. For the larger doped clusters, it is suggested that multiple isomers coexist and contribute to the experimental spectra. The structural evolution of $\mathrm{Si}_{n} \mathrm{Nb}^{+}$clusters is similar to $\mathrm{V}$-doped silicon clusters (J. Am. Chem. Soc., 2010, 132, 15589-15602), except for the largest size investigated $(n=12)$, since $\mathrm{V}$ takes an endohedral position in $\mathrm{Si}_{12} \mathrm{~V}^{+}$. The interaction with a $\mathrm{Nb}$ atom, with its partially unfilled $4 \mathrm{~d}$ orbitals leads to a significant stability enhancement of the $\mathrm{Si}_{n}$ framework as reflected, e.g. by high binding energies and large HOMO-LUMO gaps.
\end{abstract}

\section{Introduction}

Over the past few decades, scientific interest in clusters has rapidly increased, as they constitute a class of materials with fascinating physical and chemical properties, which are distinct from those of individual atoms, molecules or bulk matter. ${ }^{1-5}$ In particular, clusters of the semiconductor material silicon have attracted a lot of theoretical and experimental attention due to their potential applications in the modern microelectronics industry. ${ }^{6-12}$ Different from carbon clusters that usually show

\footnotetext{
${ }^{a}$ The Key Laboratory for Surface Engineering and Remanufacturing in Shaanxi Province, School of Chemical Engineering, Xi'an University, Xi'an 710065, Shaanxi, P. R. China. E-mail: xjli@xawl.edu.cn

${ }^{b}$ Laboratory of Solid State Physics and Magnetism, KU Leuven, B-3001 Leuven, Belgium. E-mail: ewald.janssens@fys.kuleuven.be

${ }^{c}$ Fritz-Haber-Institut der Max-Planck-Gesellschaft, Faradayweg 4-6, D-14195 Berlin, Germany

${ }^{d}$ Institut für Optik und Atomare Physik, Technische Universität Berlin, Hardenbergstr. 36, D-10623 Berlin, Germany. E-mail: fielicke@physik.tu-berlin.de $\dagger$ Electronic supplementary information (ESI) available: Comparison of calculated relative energies without and with the inclusion of zero-point vibrational energy for selected clusters; average $\mathrm{Si}-\mathrm{Si}$ and $\mathrm{Nb}-\mathrm{Si}$ bond distances and coordination numbers of $\mathrm{Nb}$ and $\mathrm{Si}$ atoms in the doped clusters; natural charge population and natural electron configuration on the $\mathrm{Nb}$ dopant; comparison of the calculated (scaled) IR spectra of the low-lying isomers and their cluster-Ar complexes for selected clusters; comparison of experimental IR-MPD spectra of $\mathrm{Si}_{n} \mathrm{Nb}^{+}-\mathrm{Ar}(n=4-7)$ and the corresponding calculated IR spectra of the low-lying isomers; the total density of states (DOS) and the partial density of states (PDOS) for $\mathrm{Si}_{4} \mathrm{Nb}^{+}$and $\mathrm{Si}_{11} \mathrm{Nb}^{+}$clusters; and the optimized Cartesian coordinates of low-lying isomers of all doped clusters. See DOI: $10.1039 / \mathrm{c} 5 \mathrm{cp} 07298 \mathrm{k}$
}

$\mathrm{sp}^{2}$ hybridization, bonding in pure silicon clusters occurs through $\mathrm{sp}^{3}$ hybridization and thus they are more chemically reactive due to the existence of unsaturated dangling bonds on the clusters' surface, making them less suitable as nanoscale building blocks. ${ }^{13}$ However, it has been found that silicon clusters can be stabilized by doping with transition metal (TM) atoms, ${ }^{14-16}$ and by now a great number of studies, both experimentally ${ }^{17-29}$ and theoretically, ${ }^{30-36}$ have explored the structures and electronic properties of TM-doped silicon clusters for their potential use in silicon-based nanomaterials. In fact, doping silicon clusters with appropriate transition metal atoms ${ }^{37-41}$ can reduce the number of dangling bonds on the cluster surface or even fully saturate them via pd hybridization, and thereby change the geometrical structures and chemical reactivities compared to pure silicon clusters. Accordingly, novel physical and chemical properties of transition-metal doped silicon clusters, e.g., size-specific stability, ${ }^{30,42}$ magnetic, ${ }^{17,28,37,39,43}$ and optical properties, ${ }^{44}$ open up many new and exciting applications, for instance, for silicon-based nano-devices in optoelectronics, tunable lasers, and sensors.

For example, Hiura et al. ${ }^{11}$ reported the formation of a series of silicon cage clusters with endohedral TM atoms, TM@Si ${ }_{n}^{+}$ (TM = Hf, Ta, W, Re, Ir, etc.), and showed by density functional theory (DFT) calculations that $\mathrm{W} @ \mathrm{Si}_{12}$ is a very stable cluster due to both electronic and geometrical shell closures. Endohedral $\mathrm{TM} @ \mathrm{Si}_{n}(\mathrm{TM}=\mathrm{W}, \mathrm{Zr}$, Os, Pt, Co) clusters have been extensively investigated theoretically, in order to test their potential as selfassembly building blocks. ${ }^{15,24,45,46}$ The properties of the endohedral clusters were shown to depend largely on the cluster size 
and the type of TM atoms. ${ }^{37,47}$ Silicon clusters doped with a lanthanide atom retaining a partially filled $4 \mathrm{f}$ shell, such as $\mathrm{Si}_{n} \mathrm{Ln}^{-}$( $\left.\mathrm{Ln}=\mathrm{Ho}, \mathrm{Gd}, \mathrm{Pr}, \mathrm{Sm}, \mathrm{Eu}, \mathrm{Yb}\right)$, have been suggested as magnetic silicon-based nanomaterials. ${ }^{17}$ Interestingly, the fully TM-encapsulated silicon clusters, TM@Si ${ }_{16}(\mathrm{TM}=\mathrm{Ti}$ and $\mathrm{Zr})$, are also predicted to exhibit luminescence in the visible range, making them attractive for optoelectronic applications, ${ }^{44}$ and the neutral $\mathrm{TiSi}_{16}$ cluster has a closed-shell electron configuration with a large gap between the highest occupied molecular orbital (HOMO) and the lowest unoccupied molecular orbital (LUMO). ${ }^{18}$ The isoelectronic $\mathrm{TaSi}_{16}{ }^{+}$has been recently reported to form stable heterodimers with $\mathrm{C}_{60}$ upon deposition from the gas phase. ${ }^{48}$

Experimentally, information on relative stabilities as well as geometric and electronic structures has been obtained from mass spectrometric observations, ${ }^{18,49,50}$ reactivity experiments that probe the location of the dopant atoms, ${ }^{43,50-52}$ photodissociation experiments, ${ }^{53}$ photoelectron spectroscopy, ${ }^{17-20,50}$ and infrared spectroscopy. ${ }^{23-29}$ However, from most experimental studies detailed geometrical information cannot be directly deduced and comparison with theoretically predicted properties is required for structural assignments. For example, from experimental infrared spectra obtained using either IR multiple photon dissociation or IR-UV two-color ionization together with theoretical studies the structures for neutral $\mathrm{Si}_{n} \mathrm{TM}(\mathrm{TM}=\mathrm{V}, \mathrm{Mn}, \mathrm{Co})^{23,24}$ and cationic $\mathrm{Si}_{n} \mathrm{TM}^{+}(\mathrm{TM}=\mathrm{V}, \mathrm{Mn}, \mathrm{Cu}, \mathrm{Ag}, \mathrm{Au})^{25-29}$ have been determined. The comparison with the experimental findings also allows to test the suitability of different theoretical approaches for predicting the ground state structures.

In general, there is still only limited systematic understanding of how doping with different TMs influences structural properties and, in particular, the chemical bonding in the doped clusters, although this may be seen as a prerequisite for designing siliconbased nanomaterials with tailor-made properties. Previous studies $^{25,27,29}$ on $\mathrm{Cu}, \mathrm{Ag}$, and Au doped Si clusters allow for a direct comparison of the effects of the different coinage metal dopants. Overall, for these three metals rather similar structures are assigned for the doped clusters, having the dopants at lowcoordinated sites due to the similar electronic configuration with completely filled d orbitals. Gradual differences between the binding behavior of $\mathrm{Cu} \mathrm{Ag}$, and $\mathrm{Au}$ are due to the larger atomic radii of the latter two atoms. In contrast to the coinage metals, $\mathrm{V}$ with an $[\mathrm{Ar}] 3 \mathrm{~d}^{3} 4 \mathrm{~s}^{2}$ atomic configuration is able to accept more electrons to participate in the chemical bonding, which is reflected in a higher coordination of the $\mathrm{V}$ dopant in silicon clusters. ${ }^{27}$ In this paper, we focus on $\mathrm{Nb}$, having a $[\mathrm{Kr}] 4 \mathrm{~d}^{4} 5 \mathrm{~s}^{1}$ atomic ground state, as a dopant. The question is raised in how far the different atomic configuration of $\mathrm{Nb}$ or the larger atomic radius (198 pm vs. $171 \mathrm{pm}$ ) may affect the structures of the doped clusters compared to its lighter homologue V.

In the following sections, we report on a combined experimental and theoretical study investigating the structures, stabilities, and electronic properties of cationic $\mathrm{Nb}$-doped silicon clusters, $\mathrm{Si}_{n} \mathrm{Nb}^{+}(n=4-12)$, applying infrared multiple photon dissociation (IR-MPD) spectroscopy to the cationic clusterAr complexes together with density functional theory (DFT) calculations.

\section{Experimental and theoretical methods}

\subsection{Experimental methods}

The experiments are performed in a molecular beam setup, which contains a dual laser vaporization source ${ }^{54}$ and a time-offlight mass spectrometer equipped for infrared (IR) excitation experiments. ${ }^{55}$ The setup has been connected to a beamline of the Free Electron Laser for Infrared experiments (FELIX) in Nieuwegein, which recently has been moved to the RU Nijmegen, the Netherlands. ${ }^{56}$ The source parameters are optimized for the formation of cold singly niobium doped silicon clusters. Argon atoms, which act as messenger atoms, are attached to the clusters to record the IR spectra of the clusters in the gas phase. The formation of cluster-argon complexes is induced at $\sim 100 \mathrm{~K}$ by the addition of a fraction of $\sim 2 \%$ of Ar to the He carrier gas, respectively. Resonant absorption of IR photons and subsequent vibrational energy redistribution heat the clusters and may result in evaporation of the weakly bound rare gas atom. The IR-MPD spectra are constructed by recording the ion intensities of the cluster-rare gas complexes as a function of the FELIX frequency in the $260-590 \mathrm{~cm}^{-1}$ range. From the depletion spectra, IR absorption spectra are calculated as described previously. ${ }^{55}$

\subsection{Theoretical methods}

To aid structural assignments, the low-lying structures of the cationic $\mathrm{Si}_{n} \mathrm{Nb}^{+}(n=4-12)$ clusters were searched using the stochastic 'random kick' procedure, ${ }^{57,58}$ interfaced with the Gaussian 09 program. $^{59}$ The procedure starts with random structures for each cluster size. Then the 'kick' procedure is performed to generate a large number of possible starting geometries that are used for further local optimizations, within a sphere-shell with the radius between $R_{\min }$ and $R_{\max }\left(R_{\min }=0, R_{\max }=4-7 \AA\right)$. This is repeated until no new minima appeared. The choice of $R_{\max }$ is chosen to be 2-3 times the $\mathrm{Si}-\mathrm{Si}$ or $\mathrm{Si}-\mathrm{Nb}$ bond length; the minimum distance $\left(D_{\text {min }}\right)$ between two atoms is set to be $2.0 \AA$, which is smaller than the $\mathrm{Si}-\mathrm{Si}$ or $\mathrm{Si}-\mathrm{Nb}$ bond length. ${ }^{60}$ All kicked structures were optimized by DFT with the pure GGA functional BP86 ${ }^{61,62}$ in conjunction with def-SVP basis sets for energy evaluation. This computational level has proven to reproduce well the experimentally observed spectra for different TM-doped silicon clusters, such as $\mathrm{Si}_{n} \mathrm{Ag}^{+}(n=6-15),{ }^{29} \mathrm{Si}_{n} \mathrm{~V}^{+}$ $(n=4-11)$ and $\mathrm{Si}_{n} \mathrm{Cu}^{+}(n=6-11){ }^{27}$ In the latter study, however, it was found that relative energies are better predicted by the hybrid functional B3LYP. ${ }^{61,63}$ In order to obtain a reasonable probability for predicting the global minimum (GM), each cluster size was searched two or three times by using the stochastic 'kick' procedure with different $R_{\max }$. All initial optimizations were carried out without symmetry constraint, and singlet and triplet spin states were examined for each starting structure. If any local minimum is found to have a specific symmetry, the structure was reoptimized again within that symmetry. Vibrational frequency analyses were employed to confirm that these structures are true minima. To aid the visual comparison with the experimental spectra the calculated infrared stick spectra were convoluted with a Gaussian function with a full width at half-maximum 
(FWHM) of $10 \mathrm{~cm}^{-1}$. In order to fit well with the experimental data a frequency scaling factor of 1.04 was applied, similar to previous studies. ${ }^{9,27,29,64}$

The reported relative energies of the Nb-doped silicon clusters do not include zero-point vibrational energies (ZPVE) as they are small and almost provide the same energetic ordering (see the energy evaluation for BP86 and B3LYP methods shown in Table S1 of the ESI $\dagger$ ). To test the influence of the $\mathrm{Ar}$ ligand, calculations were performed on cluster-Ar complexes for selected cluster sizes. The results show that Ar does not affect the energetic ordering for most low-energy isomers, with the exception of $\mathrm{Si}_{11} \mathrm{Nb}^{+}$and has only a minor effect on the vibrational frequencies and infrared intensities (see Fig. S1(a-d) of the ESI $\dagger$ ). One of the largest $\mathrm{Ar}$ induced shifts is observed for the $\mathrm{Si}_{12} \mathrm{Nb}^{+}$cluster, which is subjected to a small blue shift of less than $9 \mathrm{~cm}^{-1}$ for the high-frequency region (see Fig. S1(d) of the ESI $\dagger$ ).

\section{Results and discussion}

In this section, we first present the experimental IR-MPD spectra in the $260-590 \mathrm{~cm}^{-1}$ range and compare them with the calculated infrared spectra of different low-lying isomers to obtain structural assignments for the cationic $\mathrm{Si}_{n} \mathrm{Nb}^{+}(n=4-12)$ clusters. The identified low-lying structures for each cluster size are labeled as iso1, iso2, iso3, etc., along with increasing relative energies obtained at the BP86/def-SVP level of theory. For the smallest cluster sizes $(n=4-6)$ a favorable agreement between the experimental spectra and the ones calculated for the putative ground states is obtained and the energy gaps to higher isomers are large. Therefore these are only briefly discussed. For some cases, such as $\mathrm{Si}_{7} \mathrm{Nb}^{+}$and $\mathrm{Si}_{12} \mathrm{Nb}^{+}$, additional calculations are performed using the B3LYP functional (full optimization) to verify the relative stabilities of the low-lying isomers. Further on, the clusters' growth mechanism, electronic structure and bonding are discussed in detail. We estimate the error in the given experimental frequencies to be about $\pm 2 \mathrm{~cm}^{-1}$, mainly stemming from uncertainties in determining the band positions and errors in the calibration of the IR frequencies.

\subsection{Structure determination}

$\mathbf{S i}_{4} \mathbf{N b}^{+}$. As shown in Fig. 1, the experimental IR-MPD spectrum of $\mathrm{Si}_{4} \mathrm{Nb}^{+}$-Ar has a comparably low signal/noise ratio but clearly shows a band at around $410 \mathrm{~cm}^{-1}$. The theoretical prediction revealed that the lowest-energy structure iso1, a $C_{3 \mathrm{v}}$ symmetric trigonal bipyramid with the $\mathrm{Nb}$ at one apex with singlet ${ }^{1} \mathrm{~A}_{1}$ electronic state, reproduces well the experimental observation. The most intense band of iso1 at $414 \mathrm{~cm}^{-1}\left(\mathrm{~A}_{1}\right)$ that aids the assignment corresponds to a stretching vibration of the tetrahedral $\mathrm{Si}_{4}$ moiety. The corresponding triplet state, a $C_{\mathrm{s}}$-symmetrical structure $\left({ }^{3} \mathrm{~A}^{\prime}\right)$ is less stable in energy by $1.20 \mathrm{eV}$. Other structural isomers are at least $0.8 \mathrm{eV}$ above the putative ground state and their spectra do not fit the experimental data (Fig. S2 of the ESI $\dagger$ ). The structure assigned for $\mathrm{Si}_{4} \mathrm{Nb}^{+}$is consistent with that of $\mathrm{Si}_{4} \mathrm{~V}^{+}{ }^{27}$

$\mathbf{S i}_{5} \mathbf{N b}^{+}$. The experimental IR spectrum of $\mathrm{Si}_{5} \mathrm{Nb}^{+}-\mathrm{Ar}$ also is of moderate quality only, but it shows considerably more bands

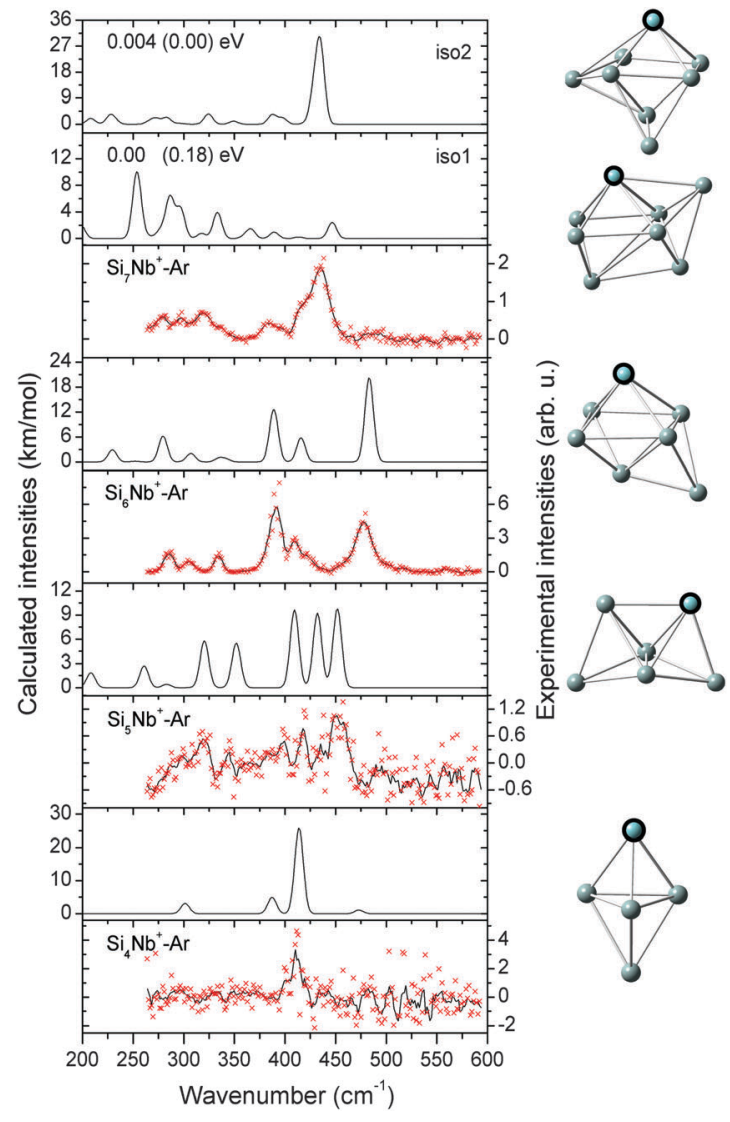

Fig. 1 Comparison of experimental IR-MPD spectra (data points [red] together with 5-point running average [black line], right axis) of $\mathrm{Si}_{n} \mathrm{Nb}^{+}-$ $\operatorname{Ar}(n=4-7)$ and the corresponding calculated IR spectra (left axis). For $\mathrm{Si}_{7} \mathrm{Nb}^{+}$the relative energies for two isomers are given at the BP86/def-SVP level of theory and at the B3LYP/def-SVP (in parentheses) level of theory. The assigned structures are shown on the right-side of the corresponding spectra.

than $\mathrm{Si}_{4} \mathrm{Nb}^{+}-\mathrm{Ar}$ with maxima around $320,345,400,420$, and $450 \mathrm{~cm}^{-1}$ (Fig. 1). The overall pattern is well reproduced by the lowest-energy structure iso1 with singlet ${ }^{1} \mathrm{~A}^{\prime}$ state in $C_{\mathrm{s}}$ symmetry, which is also similar to the structure of the $\mathrm{Si}_{5} \mathrm{~V}^{+}$ cluster, ${ }^{27}$ and can be regarded as a Si atom capping a facet of the $\mathrm{Si}_{4} \mathrm{Nb}^{+}$cluster. Other isomers are shown in Fig. S3 of the $\mathrm{ESI}, \dagger$ in which the iso1 structure with triplet ${ }^{3} \mathrm{~A}^{\prime \prime}$ state at $0.58 \mathrm{eV}$ is energetically closest. We can assign the experimental IR spectrum by the correspondingly predicted vibrational frequencies of iso1 at 320, 351, 408, 431, and $452 \mathrm{~cm}^{-1}$, where the latter three modes mainly originate from the $\mathrm{Si}-\mathrm{Nb}$ stretching vibration and stretching vibrations of tetrahedral $\mathrm{Si}_{4}$ and triangular $\mathrm{Si}_{3}$ moieties, respectively.

$\mathbf{S i}_{6} \mathbf{N b}^{+}$. Experimentally, the $\mathrm{Si}_{6} \mathrm{Nb}^{+}$-Ar cluster is characterized by two intense bands at around 390 and $480 \mathrm{~cm}^{-1}$ and four weaker bands at around 285, 305, 334, and $410 \mathrm{~cm}^{-1}$. This can be compared to the calculated IR spectrum of the lowest-energy isomer (Fig. 1). Additional isomers are compared in Fig. S4 of the ESI. $\dagger$ Apparently, the experimental bands are in excellent agreement with the computed spectrum of the lowest-energy structure iso1 that is a face-capped tetragonal bipyramid in $C_{\mathrm{S}}$ 
symmetry $\left({ }^{1} \mathrm{~A}^{\prime}\right.$ state). The two main experimental bands at around 390 and $480 \mathrm{~cm}^{-1}$ correspond to the calculated bands at 389 and $483 \mathrm{~cm}^{-1}$, respectively, while other weaker experimental bands are reproduced well by those predicted at $279,306,337$, and $415 \mathrm{~cm}^{-1}$, respectively. Noteworthily, the structure of $\mathrm{Si}_{6} \mathrm{Nb}^{+}$does not correspond to that of the $\mathrm{Si}_{6} \mathrm{~V}^{+}$cluster. ${ }^{27}$

$\mathbf{S i}_{7} \mathbf{N b}^{+}$. The experimental IR-MPD spectrum of $\mathrm{Si}_{7} \mathrm{Nb}^{+}-\mathrm{Ar}$ and the corresponding calculated spectra of the two lowest energy isomers are compared in Fig. 1 (more isomers are shown in Fig. S5 of the ESI $\dagger$ ). Isomers iso1 and iso2 have only $0.004 \mathrm{eV}$ energy difference at the BP86/def-SVP level of theory and can be generated by Si-capping of different faces of $\mathrm{Si}_{6} \mathrm{Nb}^{+}$. The lower energy isomer, iso1 $\left(C_{\mathrm{s}},{ }^{1} \mathrm{~A}^{\prime}\right)$, cannot explain the experimental spectrum, while iso2 $\left(C_{1},{ }^{1} \mathrm{~A}\right)$ shows at $434 \mathrm{~cm}^{-1}$ an intense peak consistent with the most intense feature in the experiment $\left(435 \mathrm{~cm}^{-1}\right)$. Using different theoretical methods the energetic order changes and indeed it turns out that at the B3LYP/def-SVP level of theory iso2 is predicted to be more stable in energy than iso1 by $0.18 \mathrm{eV}$. The intense peak predicted for iso2 mainly originates from a couple of vibrational modes, in which the $\mathrm{Si}-\mathrm{Si}$ stretching vibrations are related with the capping $\mathrm{Si}$ atom. These results indicate that the hybrid B3LYP functional may be more reliable for predicting relative energies than the BP86 functional, similar to the calculation of HOMO-LUMO gaps of other metal doped Si clusters, ${ }^{27}$ and the atomization energy of some small molecules. ${ }^{65} \mathrm{Si}_{7} \mathrm{Nb}^{+}$is another example where the structure of the $\mathrm{Nb}$ and $\mathrm{V}$ doped silicon clusters are different. For $\mathrm{Si}_{7} \mathrm{~V}^{+}$a capped pentagonal bipyramid has been assigned. ${ }^{27}$ However, the distortion of iso2 from such a structure is small.

$\mathbf{S i}_{8} \mathbf{N b}^{+}$. The theoretically calculated IR spectrum of the lowestenergy structure iso1 nicely matches the experimental IR-MPD spectrum of $\mathrm{Si}_{8} \mathrm{Nb}^{+}-\mathrm{Ar}$ (Fig. 2). The structure of iso1 is similar to that of $\mathrm{Si}_{8} \mathrm{~V}^{+27,64}$ and is a bicapped pentagonal bipyramid with the $\mathrm{Nb}$ dopant on an axial position. Similar to the sizes discussed before, the singlet states are generally more stable (typically by $>0.5 \mathrm{eV}$ ) than the corresponding triplet states. We therefore restrict the discussion to singlet electronic states. There are three isomers iso2, iso3, and iso4 close in energy to the putative ground state (within $\sim 0.1 \mathrm{eV}$ ), and in this case the B3LYP calculations do not lead to a different ground state, although the energy ordering changes. While iso1 explains the experimental spectrum already satisfactorily, minor contributions of iso2, iso3, and iso4 cannot be fully excluded as they also have their main bands at the positions of the experimental features.

$\mathbf{S i}_{\mathbf{9}} \mathbf{N b}^{+}$. The experimental IR-MPD spectrum of $\mathrm{Si}_{9} \mathrm{Nb}^{+}-\mathrm{Ar}$ displays broad bands with maxima at around 300, 400, and $440 \mathrm{~cm}^{-1}$. While iso1 and iso2 have intense bands in the spectral range of the experimental features, none of them can satisfactorily explain that IR-MPD spectrum. However, a combination of the two lowest-energy structures, iso1 and iso2, can reproduce the experimental band pattern (Fig. 3). iso2, which is found to be only $0.09 \mathrm{eV}$ higher in energy compared to iso1 has an intense peak at $442 \mathrm{~cm}^{-1}$, where also the most intense experimental peak is found, but no band in the spectrum of iso1. Isomer iso3 $(+0.09 \mathrm{eV})$ seems not to contribute because its intense peak at around $366 \mathrm{~cm}^{-1}$ is not observed in the experiment. At the B3LYP

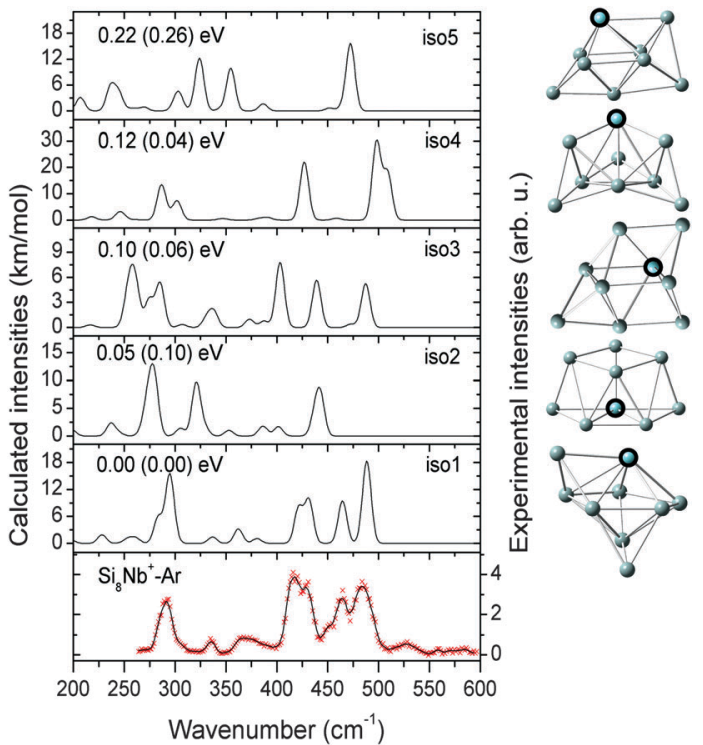

Fig. 2 Comparison of the experimental IR-MPD spectrum (data points [red] together with 5-point running average [black line], right axis) of $\mathrm{Si}_{8} \mathrm{Nb}^{+}-\mathrm{Ar}$ and the corresponding calculated IR spectra (left axis) of lowlying isomers. The isomers are ordered by their relative energies obtained at the BP86/def-SVP level of theory and the energies in parentheses are at the B3LYP/def-SVP level.

level the energy differences get more pronounced with iso2 lying $0.14 \mathrm{eV}$ and iso3 $0.20 \mathrm{eV}$ above iso1, respectively. The isomers iso4 and iso5 are significantly higher in energy and their IR spectra do not fit the experiment. Interestingly, the structures of iso1, iso2, and iso3 are all triply capped pentagonal bipyramids with the $\mathrm{Nb}$ atom on an axial position and with the same $\mathrm{Si}_{7} \mathrm{Nb}$ base, but the two additional Si atoms are adsorbed to different positions. Isomer iso2 is formed by capping the structure of the $\mathrm{Si}_{8} \mathrm{Nb}^{+}$cluster with a $\mathrm{Si}$ atom. In iso1 this additional $\mathrm{Si}$ atom is moved to an equatorial position, whereas iso3 is formed by two additional $\mathrm{Si}$ atoms symmetrically capping the $\mathrm{Si}_{7} \mathrm{Nb}$ base. As shown in Fig. 3, iso1 and iso2 are connected by a transition structure (TS) with an imaginary frequency of $58 \mathrm{i} \mathrm{cm}^{-1}$ and a Gibbs free energy barrier of $\sim 50 \mathrm{~kJ} \mathrm{~mol}^{-1}$ calculated at the BP86/def-SVP level of theory. While the barrier is probably too high for observing interconversion, the 1:1 mixture of iso1 and iso2 explains the experimental features well, and therefore both, iso1 and iso2, are assigned to co-exist in the experiment with similar abundances. For this size we have verified that the $\mathrm{Ar}$ messenger has only a minor effect on the relative energies, band positions and infrared intensities (see Fig. S1(a) of the ESI $\dagger$ ). The assigned structures are similar to the one found for $\mathrm{Si}_{9} \mathrm{~V}^{+}$, which is also based on a pentagonal bipyramid. ${ }^{27}$

$\mathbf{S i}_{10} \mathbf{N b}^{+}$. Similar to $\mathrm{Si}_{9} \mathrm{Nb}^{+}-\mathrm{Ar}$, the experimental spectrum of $\mathrm{Si}_{10} \mathrm{Nb}^{+}-\mathrm{Ar}$ exhibits broad, not well resolved bands, although the signal-to-noise ratio is reasonable (Fig. 4). The experimental IR-MPD spectrum is compared to the calculated IR spectra of the five lowest-lying $\mathrm{Si}_{10} \mathrm{Nb}^{+}$isomers iso1-iso5. Again, no single isomer can give a reasonable explanation of the experimental spectrum. There is an option that we failed to locate the correct isomer for such a large cluster. However, a $2: 1$ mixture of iso1 


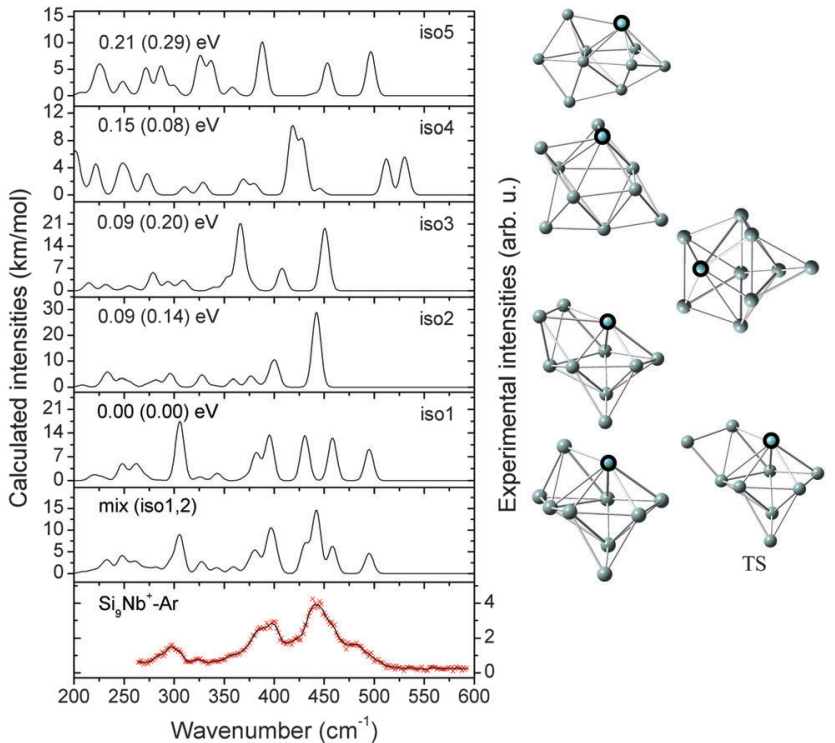

Fig. 3 Comparison of the experimental IR-MPD spectrum (data points [red] together with 5-point running average [black line], right axis) of $\mathrm{Si}_{9} \mathrm{Nb}^{+}-\mathrm{Ar}$ and the corresponding calculated IR spectra (left axis) of low-lying isomers. The mixing ratio of the mix (iso1:2) spectrum is 1:1. The relative energies are calculated at the BP86/def-SVP level of theory and at the B3LYP/def-SVP level of theory (in parentheses). The transition structure (TS) between iso1 and iso 2 is also shown.

and iso2 (BP86: $+0.10 \mathrm{eV}, \mathrm{B} 3 \mathrm{LYP}:+0.06 \mathrm{eV}$ ) may explain the IR-MPD spectrum. While the higher energy band observed at $\sim 475 \mathrm{~cm}^{-1}$ can only stem from iso2, the most intense experimental feature at $\sim 400 \mathrm{~cm}^{-1}$ may be a signature of the presence of iso1. However, the intense band of iso1 at $312 \mathrm{~cm}^{-1}$ leads to some discrepancy, as such a band is not observed in the experiment. Furthermore, the presence of iso3 (BP86: $+0.12 \mathrm{eV}$, B3LYP: $+0.17 \mathrm{eV}$ ) cannot be excluded. In particular below $375 \mathrm{~cm}^{-1}$ its calculated IR spectrum shows some features that may have their counterparts in the experimental spectrum. This gives some indications that multiple isomers may coexist for the $\mathrm{Si}_{10} \mathrm{Nb}^{+}$cluster in the experiment. Structurally, the lower-energy isomers iso1 and iso3 have a special form of a basket-like cage with the $\mathrm{Nb}$ atom in a central position of high coordination. The structure of iso1 is similar to the previously reported low-lying iso6 structure of the $\mathrm{Si}_{10} \mathrm{~V}^{+}$cluster (for this V-doped cluster no definite structural assignment has been made). ${ }^{27}$ Isomer iso2 of $\mathrm{Si}_{10} \mathrm{Nb}^{+}$can be formed by adding two $\mathrm{Si}$ atoms on two faces of the $\mathrm{Si}_{8} \mathrm{Nb}^{+}$ bicapped pentagonal bipyramid.

$\mathbf{S i}_{11} \mathbf{N b}^{+}$. The IR-MPD spectrum of $\mathrm{Si}_{11} \mathrm{Nb}^{+}-\mathrm{Ar}$ that actually shows a very favorable signal-to-noise ratio and the corresponding calculated IR spectra of the five identified lowest-lying isomers of $\mathrm{Si}_{11} \mathrm{Nb}^{+}$are shown in Fig. 5. There is no straightforward assignment possible based on a single isomer, but a combination of the three lowest energy isomers iso1, iso2, and iso3 leads to a reasonable agreement. Nevertheless, also iso4 can explain most of the experimental spectrum, the predicted spectrum is only slightly blue-shifted. However, the intense bands and shoulders in the experimental spectrum at about 380,420 , and $450 \mathrm{~cm}^{-1}$ are missing for iso4. All these isomers are comparably close in energy.

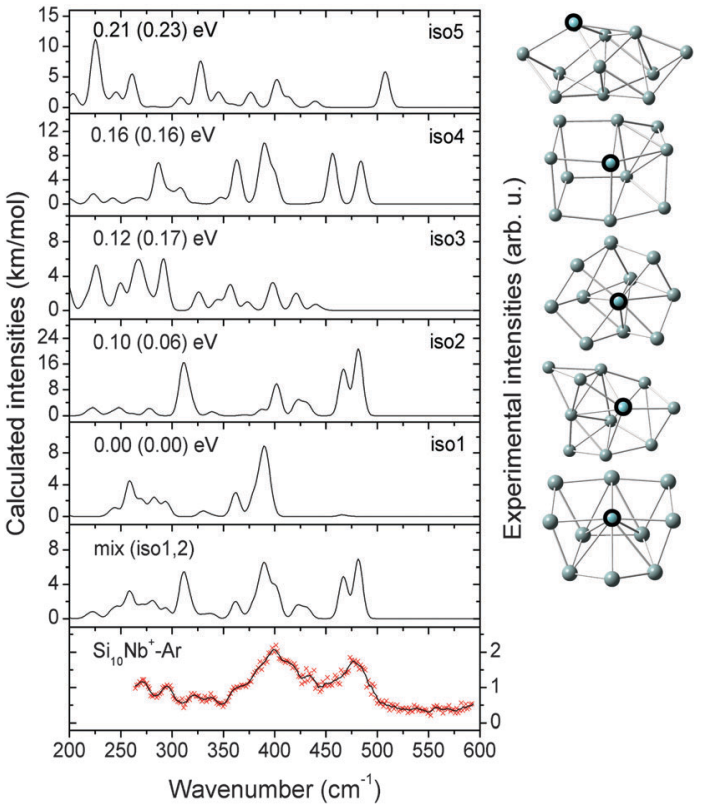

Fig. 4 Comparison of the experimental IR-MPD spectrum (data points [red] together with 5-point running average [black line], right axis) of $\mathrm{Si}_{10} \mathrm{Nb}^{+}-\mathrm{Ar}$ and the corresponding calculated IR spectra (left axis) of low-lying isomers. The mixing ratio of the mix (iso1:2) spectrum is $2: 1$. The relative energies are calculated at the BP86/def-SVP level of theory and at the B3LYP/def-SVP level of theory (in parentheses).

The lowest-energy isomer iso1 with $C_{2 \mathrm{v}}$ symmetry can be generated by Si-capping iso1 of the $\mathrm{Si}_{10} \mathrm{Nb}^{+}$cluster. iso2 and iso3 are similar to iso1 in that they contain the $\mathrm{Nb}$ atom in a high-coordinated, but not fully encapsulated, environment.

Notably, the $\mathrm{Nb}$ atom is exohedral in all low energy isomers of $\mathrm{Si}_{11} \mathrm{Nb}^{+}$, while for the vanadium doped clusters this size marks the transition from exohedral to endohedral structures. The predicted ground state for $\mathrm{Si}_{11} \mathrm{~V}^{+}$is a metal encapsulating $\mathrm{Si}$ cage, though experimentally it is found that at least a significant fraction $(\sim 50 \%)$ of it contains an exohedral $\mathrm{V}$ atom. ${ }^{27,52}$

$\mathbf{S i}_{12} \mathbf{N b}^{+}$. The five lowest-lying structures with a singlet electronic state and their calculated IR spectra are displayed in Fig. 6, in comparison with the experimental IR-MPD spectrum of $\mathrm{Si}_{11} \mathrm{Nb}^{+}-\mathrm{Ar}$. All these low-lying isomers have the $\mathrm{Nb}$ atom partly encapsulated leading to different beetle-like structures. Isomer iso4, which appears to become the ground state when using the B3LYP functional, reproduces well the experimentally observed spectrum, but the high-frequency part of the spectrum is blue-shifted by about $25 \mathrm{~cm}^{-1}$. This blue-shift may be explained by the fact that the calculated errors induced by the BP86 functional are rather random, as outlined in an earlier report, ${ }^{66}$ and sometimes this scaling factor is even slightly different for different cluster sizes, or different normal modes. ${ }^{9,27}$ It is noteworthy, that upon Ar attachment only the higher frequency band shifts to the blue by $8 \mathrm{~cm}^{-1}$, thereby leading to a similar frequency gap between the two highest energy modes as observed experimentally (see Fig. S1(d) of the ESI $\dagger$ ). The other low-energy isomers do not show good agreement with the experimental spectrum, but their contribution cannot be fully excluded as some of their peaks fit to experimental ones (iso2) 


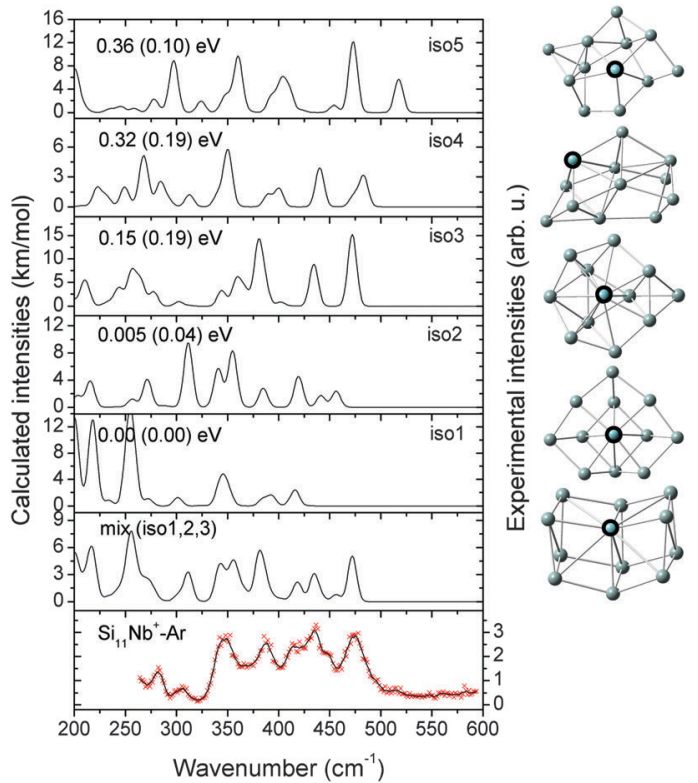

Fig. 5 Comparison of the experimental IR-MPD spectrum (data points [red] together with 5-point running average [black line], right axis) of $\mathrm{Si}_{11} \mathrm{Nb}^{+}-\mathrm{Ar}$ and the corresponding calculated IR spectra (left axis) of low-lying isomers. The mixing ratio of the mix (iso1:2:3) spectrum is $1: 1: 1$. The relative energies are calculated at the BP86/def-SVP level of theory and at the B3LYP/def-SVP level of theory (in parentheses).

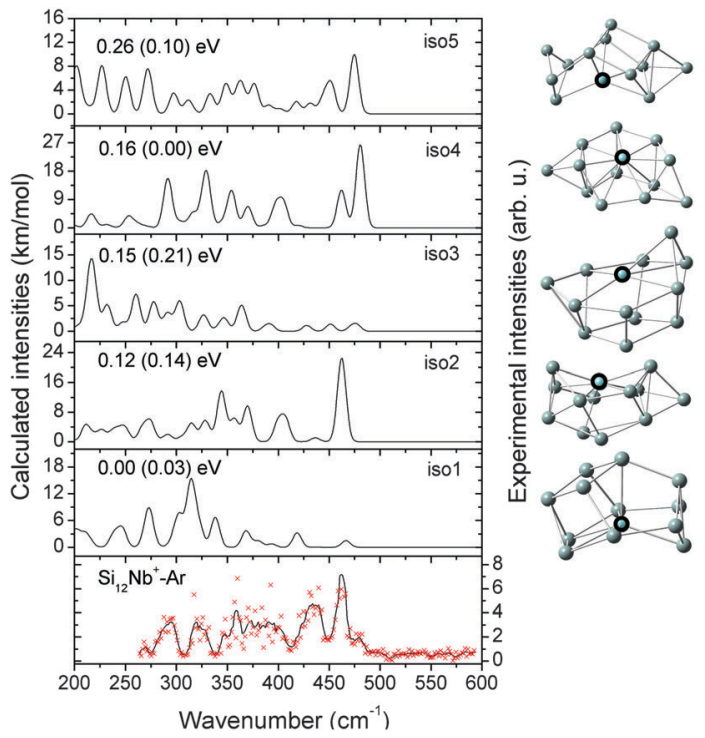

Fig. 6 Comparison of the experimental IR-MPD spectrum (data points [red] together with 5-point running average [black line], right axis) of $\mathrm{Si}_{12} \mathrm{Nb}^{+}-\mathrm{Ar}$ and the corresponding calculated IR spectra (left axis) of low-lying isomers. The relative energies are calculated at the BP86/def-SVP level of theory and at the B3LYP/def-SVP level of theory (in parentheses).

or their IR intensities are mostly low (iso1, iso3). The structure of $\mathrm{Si}_{12} \mathrm{Nb}^{+}$(iso4) is very different from that of $\mathrm{Si}_{12} \mathrm{~V}^{+}$, which has been predicted to contain an endohedral $\mathrm{V}$ atom based on the absence of Ar complex formation, ${ }^{52}$ and was later shown to have a hexagonal prism structure. ${ }^{26}$

\subsection{Structural evolution with size}

In Fig. 7 we present the structural evolution of $\mathrm{Si}_{n} \mathrm{Nb}^{+}(n=4-12)$ clusters based on the structures for the individual sizes as discussed above, in comparison with the bare $\mathrm{Si}_{n+1}{ }^{+}$and $\mathrm{Si}_{n} \mathrm{~V}^{+}$ clusters. ${ }^{9,27,67,68} \mathrm{~V}$ and $\mathrm{Nb}$ are both in group 5 of the periodic table and possess five valence electrons but having different atomic ground state configurations, i.e. $[\mathrm{Ar}] 3 \mathrm{~d}^{3} 4 \mathrm{~s}^{2}$ and $[\mathrm{Kr}] 4 \mathrm{~d}^{4} 5 \mathrm{~s}^{1}$, with closed and open s-shell, respectively, therefore it a priori is not clear if they would induce a similar geometrical structure in the doped silicon clusters. From the assignments given before, it is obvious that for the smaller sizes $\left(\mathrm{Si}_{n} \mathrm{M}^{+}\right.$with $n=4,5$ for $\mathrm{M}=\mathrm{V}$ and $\mathrm{Nb}$ ) the trigonal bipyramidal framework is maintained. ${ }^{27}$ Different from the pentagonal bipyramidal $\mathrm{Si}_{6} \mathrm{~V}^{+},{ }^{27}$ the $\mathrm{Si}_{6} \mathrm{Nb}^{+}$cluster is a capped octahedron. One can see that the larger sizes ( $\mathrm{Si}_{n} \mathrm{M}^{+}$with $n=7-10$ for $\mathrm{M}=\mathrm{V}$, and $n=7-9$ for $\mathrm{M}=\mathrm{Nb}$ ) appear as multi-capped pentagonal bipyramidal structures with a metal substitution on an axial position. When directly adding one $\mathrm{Si}$ atom to a side face of $\mathrm{Si}_{6} \mathrm{Nb}^{+}$or substituting one $\mathrm{Si}$ atom by $\mathrm{Nb}$ at an axial position of $\mathrm{Si}_{8}{ }^{+}$, the capped pentagonal bipyramidal $\mathrm{Si}_{7} \mathrm{Nb}^{+}$cluster is obtained after structural relaxation. Actually, for $n=7-9$, one Si atom always caps a face of the pentagonal bipyramid building block, while the $\mathrm{Nb}$ atom occupies the opposite apex of the bipyramid. Starting from $n=10$, one finds new structural

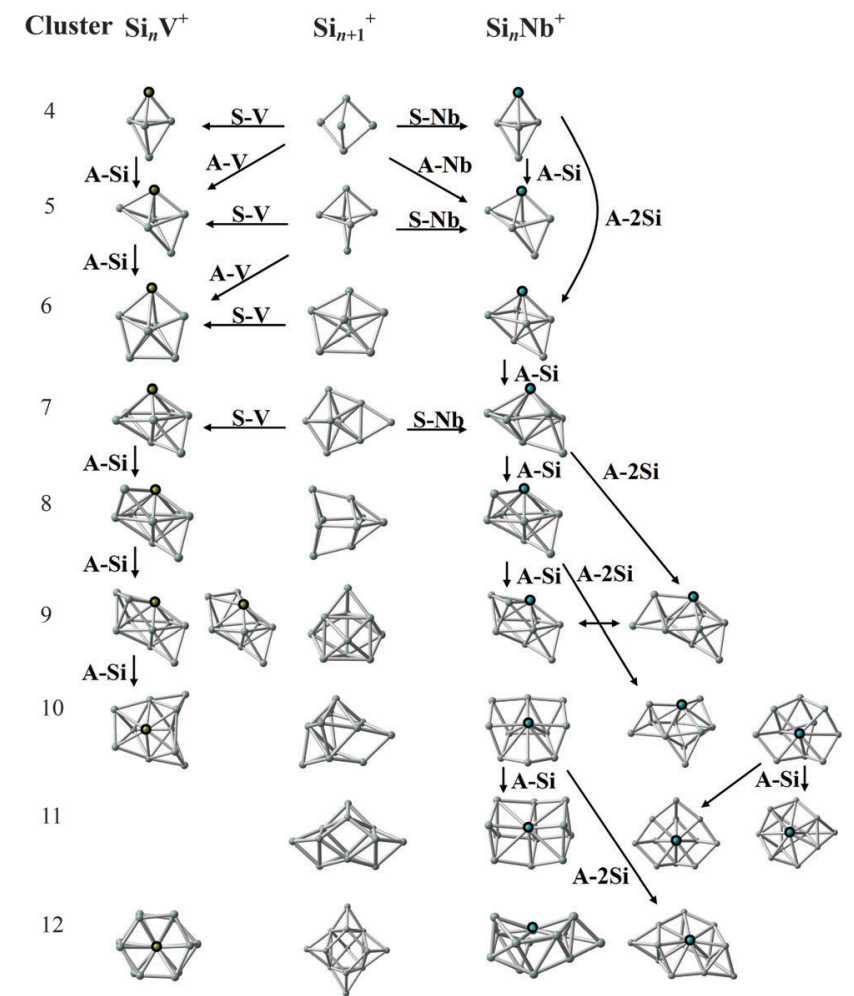

Fig. 7 Structural evolution of $\mathrm{Si}_{n} \mathrm{Nb}^{+}(n=4-12)$ clusters (right) in comparison with that of bare $\mathrm{Si}_{n+1}{ }^{+}$(middle) and $\mathrm{Si}_{n} \mathrm{~V}^{+}$(left) clusters. Arrows indicate structurally related clusters. $\mathbf{A}-\mathbf{N b}, \mathbf{A}-\mathbf{S i}$, and $\mathbf{A}-\mathbf{V}$ stand for the formal addition of a niobium, silicon, and vanadium atom. S-Nb and S-V stand for the substitution of a $\mathrm{Si}$ atom by niobium or vanadium. The structures of the bare $\mathrm{Si}_{5}{ }^{+}, \mathrm{Si}_{n+1}{ }^{+}(n=5-10,12)$, and $\mathrm{Si}_{12}{ }^{+}$clusters are taken from ref. 9,67 and 68, respectively. The structures of $\mathrm{Si}_{n} \mathrm{~V}^{+}(n=4-10)$ and $\mathrm{Si}_{12} \mathrm{~V}^{+}$clusters are taken from ref. 27 and 26 , respectively. 
forms with the $\mathrm{Nb}$ atom embedded in the surface in a 4 -fold (sometimes square) coordination, such structures are different from the V-doped silicon clusters, e.g., for which the $\mathrm{Si}_{12} \mathrm{~V}^{+}$ cluster is a distorted V-doped hexagonal prism. ${ }^{26}$

In general, the $\mathrm{Nb}$ and $\mathrm{V}$ doped silicon clusters show similar structures, except for $n=10$ and 12. Probably, the larger atomic radius of $\mathrm{Nb}$ becomes a relevant factor for the structures of the larger clusters. Structurally, the Nb dopant prefers to adsorb to an apex position of the Si framework for $n=4-9$ and takes a surface embedded position for $n=10-12$, whereas, for instance, Ag-doped clusters show similar Si frameworks but with the Ag dopants in lower coordinated apex or edge positions. ${ }^{29}$

\subsection{Relative stability of the doped clusters}

To further understand the size dependent structure and stability of the $\mathrm{Si}_{n} \mathrm{Nb}^{+}(n=4-12)$ clusters in comparison to $\mathrm{Si}_{n} \mathrm{~V}^{+}(n=4-$ $10,12)$, we evaluated the average binding energies $\left(E_{\mathrm{b}}\right)$ per atom, coordination numbers (CNs) and fragmentation energies $\left(E_{\mathrm{f}}^{1}, E_{\mathrm{f}}^{2}\right.$, and $E_{\mathrm{f}}^{3}$ ) for different fragmentation pathways, defined by:

$$
\begin{gathered}
E_{\mathrm{b}}(n)=\left[E_{\mathrm{T}}\left(\mathrm{Nb}^{+}\right)+n E_{\mathrm{T}}(\mathrm{Si})-E_{\mathrm{T}}\left(\mathrm{Si}_{n} \mathrm{Nb}^{+}\right)\right] /(n+1) \\
E_{\mathrm{f}}^{1}(n)=E_{\mathrm{T}}\left(\mathrm{Si}_{n}\right)+E_{\mathrm{T}}\left(\mathrm{Nb}^{+}\right)-E_{\mathrm{T}}\left(\mathrm{Si}_{n} \mathrm{Nb}^{+}\right) \\
E_{\mathrm{f}}^{2}(n)=E_{\mathrm{T}}\left(\mathrm{Si}_{n}^{+}\right)+E_{\mathrm{T}}(\mathrm{Nb})-E_{\mathrm{T}}\left(\mathrm{Si}_{n} \mathrm{Nb}^{+}\right) \\
E_{\mathrm{f}}^{3}(n)=E_{\mathrm{T}}\left(\mathrm{Si}_{n-1} \mathrm{Nb}^{+}\right)+E_{\mathrm{T}}(\mathrm{Si})-E_{\mathrm{T}}\left(\mathrm{Si}_{n} \mathrm{Nb}^{+}\right)
\end{gathered}
$$

where $E_{\mathrm{T}}$ represents the total energy including zero-point vibrational corrections. For $\mathrm{Si}_{n} \mathrm{Nb}^{+}(n=4-12)$, the structures that have been assigned above are considered. In cases where several isomers may contribute, only the calculated lowestenergy structure is taken for evaluating the relative stability. The structures of the bare $\mathrm{Si}_{n}{ }^{+}$and $\mathrm{Si}_{n}(n=4-12)$ clusters are taken from previous experimental and theoretical studies, ${ }^{9,12,67-70}$ and then are reoptimized at the BP86/def-SVP level of theory.

Fig. 8(a) shows that the average binding energies $E_{\mathrm{b}}$ of the Nb-doped silicon clusters increase up to the size of $n=8$ and then are nearly constant at $\sim 3.8 \mathrm{eV}$ for larger sizes. This goes along with the larger doped clusters having the Nb-atoms interacting with more $\mathrm{Si}$ atoms leading to a smaller number of dangling Si-bonds thereby stabilizing the $\mathrm{Si}_{n}$ framework. This is confirmed by the large coordination numbers of the Nb atom, as shown in Fig. 8(b) (also see Table S2 of the ESI $\dagger$ ), in which fractional coordination numbers as proposed by Grimme et al. are evaluated. ${ }^{71}$ The average binding energies of the $\mathrm{Si}_{n} \mathrm{Nb}^{+}$ clusters are higher than those of the bare $\mathrm{Si}_{n}{ }^{+}$clusters by at least $0.13 \mathrm{eV}(n=10)$, indicating that the $\mathrm{Nb}$ dopant enhances significantly the stability of the $\mathrm{Si}_{n}$ framework. By comparison, the isoelectronic $\mathrm{V}$ dopant enhances the stability (in terms of $E_{\mathrm{b}}$ ) only slightly and makes relatively weaker chemical bonds with $\mathrm{Si}$ than the $\mathrm{Nb}$. Further, the low-coordinated $\mathrm{Cu} / \mathrm{Ag}$ dopants with filled $3 \mathrm{~d} / 4 \mathrm{~d}$ orbitals are weaker bound than the $\mathrm{Nb}$ atom leading to a lower average binding energy of the doped clusters. ${ }^{27,29}$

The calculated fragmentation energies of the $\mathrm{Si}_{n} \mathrm{Nb}^{+}$clusters, plotted in Fig. 8(c), show that the loss of the $\mathrm{Nb}^{+}$cation or the $\mathrm{Nb}$ atom is in all cases unfavorable compared to the loss of a single $\mathrm{Si}$ atom. This is different compared to $\mathrm{Si}_{n} \mathrm{~V}^{+}$clusters

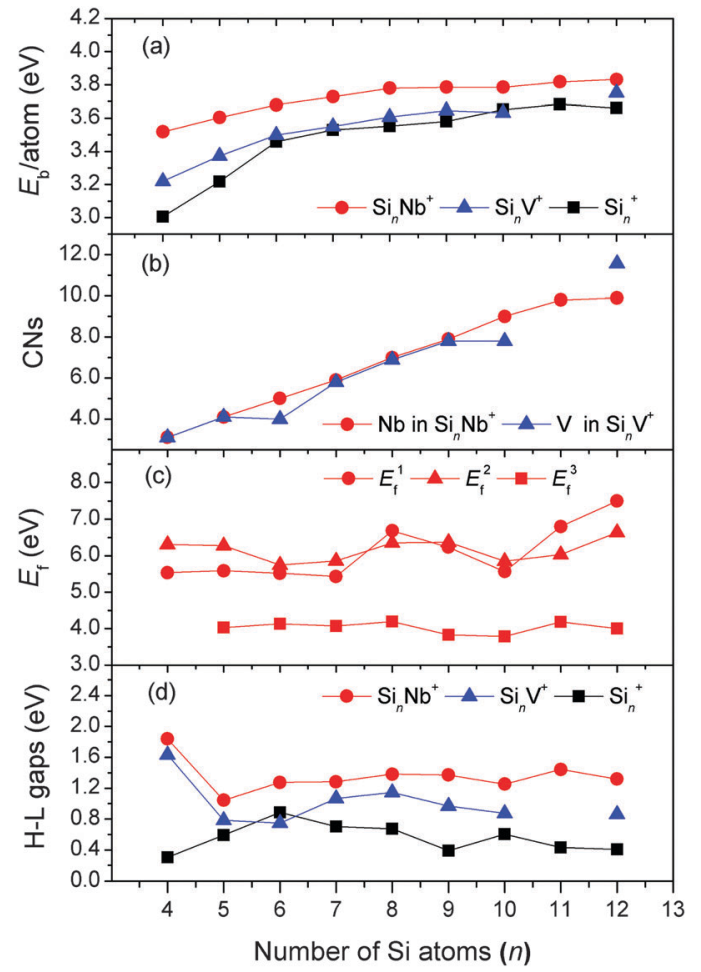

Fig. 8 Evolution of different energy parameters and of the coordination numbers as a function of cluster size. (a) The average binding energy $\left(E_{\mathrm{b}}\right)$ per atom for $\mathrm{Si}_{n} \mathrm{Nb}^{+}, \mathrm{Si}_{n} \mathrm{~V}^{+}$, and $\mathrm{Si}_{n}{ }^{+}$; (b) the coordination number (CN) of $\mathrm{Nb}$ in $\mathrm{Si}_{n} \mathrm{Nb}^{+}$and $\mathrm{V}$ in $\mathrm{Si}_{n} \mathrm{~V}^{+}$; (c) the fragmentation energies $\left(E_{\mathrm{f}}\right)$ for three fragmentation pathways of $\mathrm{Si}_{n} \mathrm{Nb}^{+}$: removal of (i) a $\mathrm{Nb}^{+}$cation $\left(E_{\mathrm{f}}^{1}\right)$, (ii) a $\mathrm{Nb}$ atom $\left(E_{\mathrm{f}}^{2}\right)$, and (iii) a Si atom $\left(E_{\mathrm{f}}^{3}\right)$; (d) HOMO-LUMO energy gaps ( $\mathrm{H}-\mathrm{L}$ gaps) of $\mathrm{Si}_{n} \mathrm{Nb}^{+}, \mathrm{Si}_{n} \mathrm{~V}^{+}$, and $\mathrm{Si}_{n}{ }^{+}$. The energies of $\mathrm{Si}_{n} \mathrm{~V}^{+}(n=4-10,12)$ are obtained from the reoptimization at the BP86/def-SVP level of theory, based on the structures in ref. 26 and 27. Similarly, the structures of the bare $\mathrm{Si}_{n}{ }^{+}$and $\mathrm{Si}_{n}$ ( $n=4-12$ ) clusters are taken from ref. 9, 12, and 67-70, and reoptimized at the same level of theory.

where for most sizes the loss of the $\mathrm{V}$ cation is found to be the most facile fragmentation channel. ${ }^{27}$ As the atomic ionization energies of $\mathrm{V}$ and $\mathrm{Nb}$ are nearly identical (6.746 vs. $6.759 \mathrm{eV}$ ) this once more shows the significant stronger stabilization of the $\mathrm{Si}$ clusters by Nb doping.

The stabilization by $\mathrm{Nb}$ doping also becomes evident in the HOMO-LUMO gaps that are distinctly larger by up to $1.5 \mathrm{eV}$ for the $\mathrm{Si}_{n} \mathrm{Nb}^{+}$clusters than those of the bare $\mathrm{Si}_{n}{ }^{+}$clusters (Fig. 8(d)). For the $\mathrm{Si}_{n} \mathrm{~V}^{+}$clusters the gap is slightly smaller and for $\mathrm{Si}_{6} \mathrm{~V}^{+}$ even lower compared to the bare Si clusters. Local maxima for the HOMO-LUMO gaps are found for $\mathrm{Si}_{4} \mathrm{Nb}^{+}$and $\mathrm{Si}_{11} \mathrm{Nb}^{+}$. To further understand the effect of $\mathrm{Nb}$ doping, we have performed a detailed analysis of the frontier molecular orbitals by probing the partial density of states (PDOS, plotted in Fig. S6 of the $\mathrm{ESI} \dagger$ ), in which the contributions of different atomic shells (s, p, d) to the molecular orbitals are analyzed. From the NBO analysis performed for the $\mathrm{Si}_{4} \mathrm{Nb}^{+}$cluster one recognizes that its HOMO originates mainly from the $\mathrm{Si} 3 \mathrm{p}_{z}$-states (53\%) mixed with $\mathrm{Si} 3 \mathrm{~s}(23 \%)$ and $\mathrm{Nb} 4 \mathrm{~d}_{z^{2}}(7 \%)$ states, whereas the LUMO state contains mainly $\mathrm{Si} 3 \mathrm{p}_{y}(33 \%)$ and $\mathrm{Nb} 4 \mathrm{~d}_{x^{2}-y^{2}}(43 \%)$ states. The Si 3s-states contribute only little. Interestingly, for the 
$\mathrm{Si}_{11} \mathrm{Nb}^{+}$cluster, the HOMO state is mainly composed of $\mathrm{Si} 3 \mathrm{p}_{x}$ (27\%) and $\mathrm{Si} 3 \mathrm{p}_{y}(25 \%)$ states mixed with a relatively large contribution of $\mathrm{Nb} 4 \mathrm{~d}_{z^{2}}(15 \%)$ states, whereas the LUMO states are largely delocalized around the Si surface of the structure. The large HOMO-LUMO gaps may be related to this pronounced hybridization of $\mathrm{Si} 3 \mathrm{p}$ and $\mathrm{Nb} 4 \mathrm{~d}$ states. A similar behavior is also observed for other cluster sizes.

3.4 Charge-transfer mechanisms. We performed a natural population analysis to explore the charge-transfer mechanism and electronic configuration of the $\mathrm{Nb}$ atom in the $\mathrm{Nb}$-doped silicon clusters (see Table S3 of the ESI $\dagger$ ), using the NBO 3.1 program. ${ }^{72}$ It was found that the direction of charge-transfer depends on the size of the Nb-doped silicon clusters, a behavior similar to that found for the $\mathrm{Si}_{n} \mathrm{M}^{0 /+}$ with $M=$ Ta and $\mathrm{Zr}^{73-75}$ In the case of the small Nb-doped silicon clusters (e.g., $\mathrm{Si}_{4} \mathrm{Nb}^{+}$and $\mathrm{Si}_{5} \mathrm{Nb}^{+}$) there is a slight electron transfer from the $\mathrm{Nb}$ atom to the Si framework. The charge-transfer direction is changed for the larger $\mathrm{Si}_{n} \mathrm{Nb}^{+}(n=6-12)$ clusters with negative charges on the $\mathrm{Nb}$ atom that gradually increase with cluster size. Noteworthily, the charge-transfer direction may not only depend on the cluster size and the dopant, but even on the overall charge state of the cluster, see $e . g$. the findings for $\mathrm{Si}_{n} \mathrm{La}^{-, 0,+}(n=1-21){ }^{76}$

This increasing electron transfer towards the $\mathrm{Nb}$ dopant becomes apparent also in the occupation of the $4 \mathrm{~d}$ orbitals of $\mathrm{Nb}$. The occupation of these orbitals increases with cluster size from $4.41 e$ for $n=5$ (4.41) to $5.58 e$ for $n=11$, which is higher than in the $4 \mathrm{~d}$ orbitals (4.0) of the isolated $\mathrm{Nb}$ atom (for details see Table S3 of the ESI $\dagger$ ). The $\mathrm{Nb}$ atoms (similar for $\mathrm{V}$ ) always locate at high coordination positions in the Si frameworks as shown in Fig. 7. Therefore, bonding to the Si framework must involve the $4 \mathrm{~d}$ orbitals leading to a rise of their occupation along with an increase of the coordination number. Thereby the high coordination numbers appear to be a reason for the increasing stabilization of the doped clusters. In comparison, for $\mathrm{Cu}$ and $\mathrm{Ag}$ doped silicon clusters the natural populations of the metals' d orbitals are about 9.8 and 9.9, respectively, indicating that the $\mathrm{d}$ orbitals are not significantly involved in chemical bonding, and the $\mathrm{Cu}$ and $\mathrm{Ag}$ atoms favor low coordination in the doped silicon clusters. ${ }^{27,29}$

\section{Conclusions}

In conclusion, we have performed a systematic experimental and DFT study on cationic Nb-doped silicon clusters, $\mathrm{Si}_{n} \mathrm{Nb}^{+}$ ( $n=4-12)$, to obtain insights into their structures and stabilities. Infrared spectra are obtained using multiple photon dissociation of the cluster-argon complexes and are compared to calculated harmonic IR spectra. In most cases, good agreement is found when using the BP86 functional and the spectra are assigned to the lowest-energy structures identified in the calculations. However, for certain sizes, higher energy isomers need to be considered to explain the experimental spectra. Here, the hybrid functional B3LYP is found to give a more reliable energy ordering. While up to the size of $\mathrm{Si}_{8} \mathrm{Nb}^{+}$the experimental spectra are well explained by considering a single isomer, for the larger clusters multiple isomers appear to be present in the experiment. Structurally, it is found that the $\mathrm{Nb}$ dopant tends to adsorb to an apex position of the Si framework for $n=4-9$, showing the same structural evolution like the $\mathrm{Si}_{n} \mathrm{~V}^{+}$clusters with the only exception of $\mathrm{Si}_{6} \mathrm{~V}^{+}$, and a high-coordination surface position for $n=10-12$. Thus, at least up to the size of $\mathrm{Si}_{12} \mathrm{Nb}^{+}$, where the $\mathrm{V}$ doped species is already endohedral, only exohedral structures are identified. The analysis of binding energies and HOMO-LUMO gaps indicates that doping with $\mathrm{Nb}$ atoms leads to a significant stabilization compared to the pure silicon cluster, as observed for the V-dopant. Furthermore, the predicted lowest energy fragmentation channel for these clusters is the loss of Si atoms, due to the high stability of the Nb-doped clusters.

\section{Note added in proof}

A recent publication ${ }^{77}$ also reported the structures of cationic niobium-doped silicon clusters, but some of their predicted structures are not supported by our analysis, based on the experimental IR-MPD spectroscopy and DFT calculations. In that paper published by Xia et al., ${ }^{77}$ the lowest-energy structures and spin states of the cationic niobium-doped silicon clusters are in good agreement with those with $n=4,6$, and 11 reported here, but disagree with those with $n=5,7,8,9,10$, and 12, as identified by IR-MPD spectroscopy.

\section{Acknowledgements}

The authors gratefully acknowledge the support from the Stichting voor Fundamenteel Onderzoek der Materie (FOM) in providing beam time on FELIX and highly appreciate the skillful assistance of the FELIX staff. This work is supported by the European Community's FP7/2007-2013 (Grant No. 226716), the Research Foundation-Flanders (FWO, grant G.0B41.15), the KU Leuven Research Council (GOA/14/007) program, and the Deutsche Forschungsgemeinschaft within FOR 1282 (FI 893/4). We gratefully acknowledge the financial support from the Natural Science Foundation of Shaanxi Province (No. 2014JM2-2019), the Natural Science Foundation of Education Department of Shaanxi Province (No. 14JK2128), and the Special Natural Science Foundation of Science and Technology Bureau of Xi'an City (No. CXY1352WL20).

\section{References}

1 R. Ferrando, J. Jellinek and R. L. Johnston, Chem. Rev., 2008, 108, 845-910.

2 P. Gruene, D. M. Rayner, B. Redlich, A. F. G. van der Meer, J. T. Lyon, G. Meijer and A. Fielicke, Science, 2008, 321, 674-676.

3 S. Scharfe, F. Kraus, S. Stegmaier, A. Schier and T. F. Fässler, Angew. Chem., Int. Ed., 2011, 50, 3630-3670.

4 E. C. Honea, A. Ogura, C. A. Murray, K. Raghavachari, W. O. Sprenger, M. F. Jarrold and W. L. Brown, Nature, 1993, 366, 42-44.

5 A. H. Lu, E. L. Salabas and F. Schüth, Angew. Chem., Int. Ed., 2007, 46, 1222-1244. 
6 L. X. Benedict, A. Puzder, A. J. Williamson, J. C. Grossman, G. Galli, J. E. Klepeis, J.-Y. Raty and O. Pankratov, Phys. Rev. B: Condens. Matter Mater. Phys., 2003, 68, 085310.

7 K.-M. Ho, A. A. Shvartsburg, B. Pan, Z.-Y. Lu, C.-Z. Wang, J. G. Wacker, J. L. Fye and M. F. Jarrold, Nature, 1998, 392, 582-585.

8 M. Scheer, R. C. Bilodeau, C. A. Brodie and H. K. Haugen, Phys. Rev. A: At., Mol., Opt. Phys., 1998, 58, 2844.

9 J. T. Lyon, P. Gruene, A. Fielicke, G. Meijer, E. Janssens, P. Claes and P. Lievens, J. Am. Chem. Soc., 2009, 131, 1115-1121.

10 D. A. Götz, S. Heiles and R. Schäfer, Eur. Phys. J. D, 2012, 66, 293.

11 H. Hiura, T. Miyazaki and T. Kanayama, Phys. Rev. Lett., 2001, 86, 1733.

12 M. Haertelt, J. T. Lyon, P. Claes, J. de Haeck, P. Lievens and A. Fielicke, J. Chem. Phys., 2012, 136, 064301.

13 U. Röthlisberger, W. Andreoni and M. Parrinello, Phys. Rev. Lett., 1994, 72, 665.

14 S. M. Beck, J. Chem. Phys., 1987, 87, 4233.

15 S. M. Beck, J. Chem. Phys., 1989, 90, 6306.

16 H. T. Pham, T.-T. Phan, N. M. Tam, L. V. Duong, M. P. Pham-Ho and M. T. Nguyen, Phys. Chem. Chem. Phys., 2015, 17, 17566-17570.

17 A. Grubisic, Y. J. Ko, H. Wang and K. H. Bowen, J. Am. Chem. Soc., 2009, 131, 10783-10790.

18 K. Koyasu, M. Akutsu, M. Mitsui and A. Nakajima, J. Am. Chem. Soc., 2005, 127, 4998-4999.

19 H.-G. Xu, M. M. Wu, Z.-G. Zhang, J. Yuan, Q. Sun and W. Zheng, J. Chem. Phys., 2012, 136, 104308.

20 X. Kong, H.-G. Xu and W. Zheng, J. Chem. Phys., 2012, 137, 064307.

21 X. Huang, H.-G. Xu, S. Lu, Y. Su, R. B. King, J. Zhao and W. Zheng, Nanoscale, 2014, 6, 14617-14621.

22 X. Huang, S.-J. Lu, X. Liang, Y. Su, L. Sai, Z.-G. Zhang, J. Zhao, H.-G. Xu and W. Zheng, J. Phys. Chem. C, 2015, 119, 10987-10994.

23 P. Claes, V. T. Ngan, M. Haertelt, J. T. Lyon, A. Fielicke, M. T. Nguyen, P. Lievens and E. Janssens, J. Chem. Phys., 2013, 138, 194301.

24 Y. Li, N. M. Tam, P. Claes, A. P. Woodham, J. T. Lyon, V. T. Ngan, M. T. Nguyen, P. Lievens, A. Fielicke and E. Janssens, J. Phys. Chem. A, 2014, 118, 8198-8203.

25 Y. Li, J. T. Lyon, A. P. Woodham, P. Lievens, A. Fielicke and E. Janssens, J. Phys. Chem. C, 2015, 119, 10896-10903.

26 P. Claes, E. Janssens, V. T. Ngan, P. Gruene, J. T. Lyon, D. J. Harding, A. Fielicke, M. T. Nguyen and P. Lievens, Phys. Rev. Lett., 2011, 107, 173401.

27 V. T. Ngan, P. Gruene, P. Claes, E. Janssens, A. Fielicke, M. T. Nguyen and P. Lievens, J. Am. Chem. Soc., 2010, 132, 15589-15602.

28 V. T. Ngan, E. Janssens, P. Claes, J. T. Lyon, A. Fielicke, M. T. Nguyen and P. Lievens, Chem. - Eur. J., 2012, 18, 15788-15793.

29 Y. Li, J. T. Lyon, A. P. Woodham, A. Fielicke and E. Janssens, ChemPhysChem, 2014, 15, 328-336.

30 Q. Peng and J. Shen, J. Chem. Phys., 2008, 128, 084711.

31 L.-J. Guo, X. Liu, G.-F. Zhao and Y.-H. Luo, J. Chem. Phys., 2007, 126, 234704.

32 J. Yang, J. Wang and Y. Hao, Theor. Chem. Acc., 2015, 134, 81.
33 L. Lin and J. Yang, J. Mol. Model., 2015, 21, 155.

34 J.-R. Li, G.-H. Wang, C.-H. Yao, Y.-W. Mu, J.-G. Wan and M. Han, J. Chem. Phys., 2009, 130, 164514.

35 J.-P. Dognon, C. Clavaguéra and P. Pyykkö, Chem. Sci., 2012, 3, 2843-2848.

36 J. M. Goicoechea and J. E. McGrady, Dalton Trans., 2015, 6755-6766.

37 L. Ma, J. Zhao, J. Wang, B. Wang, Q. Lu and G. Wang, Phys. Rev. B: Condens. Matter Mater. Phys., 2006, 73, 125439.

38 J. Wang, J. Zhao, L. Ma, B. Wang and G. Wang, Phys. Lett. A, 2007, 367, 335-344.

39 J. Wang, Q.-M. Ma, Z. Xie, Y. Liu and Y.-C. Li, Phys. Rev. B: Condens. Matter Mater. Phys., 2007, 76, 035406.

40 F.-C. Chuang, Y.-Y. Hsieh, C.-C. Hsu and M. A. Albao, J. Chem. Phys., 2007, 127, 144313.

41 S. Furuse, K. Koyasu, J. Atobe and A. Nakajima, J. Chem. Phys., 2008, 129, 064311.

42 H. Kawamura, V. Kumar and Y. Kawazoe, Phys. Rev. B: Condens. Matter Mater. Phys., 2004, 70, 245433.

43 V. Zamudio-Bayer, L. Leppert, K. Hirsch, A. Langenberg, J. Rittmann, M. Kossick, M. Vogel, R. Richter, A. Terasaki, T. Möller, B. v. Issendorff, S. Kümmel and J. T. Lau, Phys. Rev. B: Condens. Matter Mater. Phys., 2013, 88, 115425.

44 V. Kumar, T. M. Briere and Y. Kawazoe, Phys. Rev. B: Condens. Matter Mater. Phys., 2003, 68, 155412.

45 V. Kumar and Y. Kawazoe, Phys. Rev. Lett., 2001, 87, 045503. 46 V. Kumar and Y. Kawazoe, Phys. Rev. B: Condens. Matter Mater. Phys., 2002, 65, 073404.

47 J. Lu and S. Nagase, Phys. Rev. Lett., 2003, 90, 115506.

48 M. Nakaya, T. Iwasa, H. Tsunoyama, T. Eguchi and A. Nakajima, J. Phys. Chem. C, 2015, 119, 10962-10968.

49 Z. Chen, S. Neukermans, X. Wang, E. Janssens, Z. Zhou, R. E. Silverans, R. B. King, P. von R. Schleyer and P. Lievens, J. Am. Chem. Soc., 2006, 128, 12829-12834.

50 M. Ohara, K. Koyasu, A. Nakajima and K. Kaya, Chem. Phys. Lett., 2003, 371, 490-497.

51 M. Ohara, K. Miyajima, A. Pramann, A. Nakajima and K. Kaya, J. Phys. Chem. A, 2002, 106, 3702-3705.

52 E. Janssens, P. Gruene, G. Meijer, L. Wöste, P. Lievens and A. Fielicke, Phys. Rev. Lett., 2007, 99, 063401.

53 J. B. Jaeger, T. D. Jaeger and M. A. Duncan, J. Phys. Chem. A, 2006, 110, 9310-9314.

54 W. Bouwen, P. Thoen, F. Vanhoutte, S. Bouckaert, F. Despa, H. Weidele, R. E. Silverans and P. Lievens, Rev. Sci. Instrum., 2000, 71, 54-55.

55 A. Fielicke, G. von Helden and G. Meijer, Eur. Phys. J. D, 2005, 34, 83-88.

56 D. Oepts, A. F. G. van der Meer and P. W. van Amersfoort, Infrared Phys. Technol., 1995, 36, 297-308.

57 M. Saunders, J. Comput. Chem., 2004, 25, 621-626.

58 J. Tong, Y. Li, D. Wu, Z.-R. Li and X.-R. Huang, J. Chem. Phys., 2009, 131, 164307.

59 M. J. Frisch, G. W. Trucks, H. B. Schlegel, G. E. Scuseria, M. A. Robb, J. R. Cheeseman, G. Scalmani, V. Barone, B. Mennucci, G. A. Petersson, H. Nakatsuji, M. Caricato, X. Li, H. P. Hratchian, A. F. Izmaylov, J. Bloino, G. Zheng, 
J. L. Sonnenberg, M. Hada, M. Ehara, K. Toyota, R. Fukuda, J. Hasegawa, M. Ishida, T. Nakajima, Y. Honda, O. Kitao, H. Nakai, T. Vreven, J. A. Montgomery, Jr, J. E. Peralta, F. Ogliaro, M. Bearpark, J. J. Heyd, E. Brothers, K. N. Kudin, V. N. Staroverov, R. Kobayashi, J. Normand, K. Raghavachari, A. Rendell, J. C. Burant, S. S. Iyengar, J. Tomasi, M. Cossi, N. Rega, J. M. Millam, M. Klene, J. E. Knox, J. B. Cross, V. Bakken, C. Adamo, J. Jaramillo, R. Gomperts, R. E. Stratmann, O. Yazyev, A. J. Austin, R. Cammi, C. Pomelli, J. W. Ochterski, R. L. Martin, K. Morokuma, V. G. Zakrzewski, G. A. Voth, P. Salvador, J. J. Dannenberg, S. Dapprich, A. D. Daniels, O. Farkas, J. B. Foresman, J. V. Ortiz, J. Cioslowski and D. J. Fox, Gaussian 09, Revision D. 01, Gaussian, Inc., Wallingford CT, 2009.

60 T. B. Tai and M. T. Nguyen, J. Chem. Theory Comput., 2011, 7, 1119-1130.

61 A. D. Becke, Phys. Rev. A: At., Mol., Opt. Phys., 1988, 38, 3098. 62 J. P. Perdew, Phys. Rev. B: Condens. Matter Mater. Phys., 1986, 33, 8822.

63 C. Lee, W. Yang and R. G. Parr, Phys. Rev. B: Condens. Matter Mater. Phys., 1988, 37, 785-789.

64 P. Gruene, A. Fielicke, G. Meijer, E. Janssens, V. T. Ngan, M. T. Nguyen and P. Lievens, ChemPhysChem, 2008, 9, 703-706. 65 C. W. Bauschlicher, Chem. Phys. Lett., 1995, 246, 40-44.
66 K. P. Jensen, B. O. Roos and U. Ryde, J. Chem. Phys., 2007, 126, 014103.

67 S. Nigam, C. Majumder and S. K. Kulshreshtha, J. Chem. Phys., 2004, 121, 7756.

68 M. Vogel, C. Kasigkeit, K. Hirsch, A. Langenberg, J. Rittmann, V. Zamudio-Bayer, A. Kulesza, R. Mitrić, T. Möller, B. v. Issendorff and J. T. Lau, Phys. Rev. B: Condens. Matter Mater. Phys., 2012, 85, 195454.

69 A. Fielicke, J. T. Lyon, M. Haertelt, G. Meijer, P. Claes, J. de Haeck and P. Lievens, J. Chem. Phys., 2009, 131, 171105.

70 A. A. Shvartsburg, B. Liu, M. F. Jarrold and K.-M. Ho, J. Chem. Phys., 2000, 112, 4517.

71 S. Grimme, J. Antony, S. Ehrlich and H. Krieg, J. Chem. Phys., 2010, 132, 154104.

72 E. D. Glendening, A. E. Reed, J. E. Carpenter and F. Weinhold, NBO Version 3.1.

73 P. Guo, Z.-Y. Ren, F. Wang, J. Bian, J.-G. Han and G.-H. Wang, J. Chem. Phys., 2004, 121, 12265.

74 J. Wang and J.-G. Han, J. Chem. Phys., 2005, 123, 064306.

75 P. Guo, Z.-Y. Ren, A.-P. Yang, J.-G. Han, J. Bian and G.-H. Wang, J. Phys. Chem. A, 2006, 110, 7453-7460.

76 Q. Peng and J. Shen, J. Chem. Phys., 2008, 128, 084711.

77 X. X. Xia, A. Hermann, X. Y. Kuang, Y. Y. Jin, C. Lu and X. D. Xing, J. Phys. Chem. C, 2016, 120, 677-684. 